\section{Differential Impacts of Caries Classification in Children and Adults: A Comparison of ICDAS and DMF-T}

Rosa Ana Melgar1, Joanna Tatith Pereira², Patrícia Blaya Luz³, Fernando

Neves Hugo 4 , Fernando Borba de Araujo ${ }^{3}$

\begin{abstract}
The aim of this study was to describe and compare findings regarding the prevalence and severity of dental caries when using ICDAS and DMFT/dmft in an epidemiological study with children and their mothers. This cross-sectional study evaluated 150 preschoolers and their mothers. Data were collected with ICDAS and then transformed into DMFT/dmft. ICDAS scores related to caries were analyzed according to three different cut-off-points: CP1 (0-healthy/1-6-caries), CP2 (0-1-healthy/2-6-caries) and CP3 (0-2-healthy/3-6caries), representing the D/d of DMFT/dmft. ICDAS codes regarding restorations, except sealants, were considered the F/f and the code 97 as the $\mathrm{M} / \mathrm{m}$ of DMFT/dmft index. Prevalence of caries and its severity with ICDAS were $92 \%, 84 \%$ and $31.3 \%$ in children and $97.3 \%, 96.6 \%$ and $80 \%$ in adults according to CP1/CP2/CP3, respectively. Admitting CP3 as the standard for data transformation of ICDAS in DMFT/dmft, it was observed that DMFT/dmft index would underestimate $60 \%$ of non-cavitated lesions in children and $16.6 \%$ in adults. The DMFT/dmft underestimated the presence of disease to disregard non-cavitated lesions for the pediatric population evaluated. The choice of which is the best index for epidemiological surveys will depend on the purpose of the research and the target population: if it is to estimate the needs of the population to determine clinical care in children and adults, the DMFT/dmft may be sufficient. However, if the objective is to have a more comprehensive diagnosis of caries at the population level in order to develop preventive strategies, to halt and reverse the disease, the detection of non-cavitated-lesions becomes important, mainly in young children.
\end{abstract}

1Faculty of Dentistry of Universidad Peruana Cayetano Heredia, Lima, Peru ${ }^{2}$ University Center of Serra Gaúcha, Caxias do Sul, RS, Brazil and UFRGS - Federal University of Rio Grande do Sul; Pediatric Dentistry, Porto Alegre, RS, Brazil 3UFRGS - Federal University of Rio Grande do Sul, Pediatric Dentistry, Porto Alegre, RS, Brazil ${ }^{4}$ UFRGS - Federal University of Rio Grande do Sul, Center of Community Dental Health Research, Porto Alegre, RS, Brazil

Correspondence: Professora Joanna Tatith Pereira, Rua São Manoel 1411/402 90620-110, Porto Alegre, RS, Brazil. Tel: +55-51-981714591. e-mail: joannatpereira@hotmail.com.

\section{Introdution}

Dental caries is the most common chronic disease of the oral cavity, which affects the population in general, from children to adults and seniors $(1,2)$. Several epidemiological population-based studies have demonstrated a significant decrease in caries worldwide, a fact that is not demonstrated when the object of the study are preschool children (3). Well-designed epidemiological studies provide a picture of the population and are important tools in defining the distribution of funds for oral health programs and the implementation of preventive policies by stakeholders (4).

Based on current knowledge of cariology and on the principles of minimal intervention, the treatment of carious lesions in the early stages occurs in a non-operative manner, avoiding the need for more complex and costly treatments (5). For this purpose, the choice of a criterion of caries detection that includes non-cavitated lesions and detect early injuries could increase sensitivity, mainly in populations with low prevalence of the disease, in which carious lesions have a low progression rate and are commonly found in the initial stages (6).

In 2004, a new system for the visual detection of caries lesions was developed for use in clinical practice and in clinical and epidemiological research - ICDAS (7). This system was feasible for epidemiological research with an acceptable degree of reliability to detect non-cavitated and cavitated lesions (7-9). The most commonly used detection criteria recommended by the World Health Organization (WHO), the DMF index, is used worldwide in dental research, but is unable to provide accurate data about lesions in the early stages (10).

Based on the minimal intervention concept, as well as in the possibility of paralyzing and reversing dental caries in the early stages, one should not restrict the detection of disease to cavitated lesions (5). Thus, the use of a method capable of identifying spot lesions and their progression over time in an epidemiological level may be relevant considering the objective to be achieved in a study. The need for operative treatment at the population or individual level may be measured by the DMF index (11-13). While this information is in itself important, when evaluated alone, it perpetuates the over past concept that the caries process should be treated by restorations and extractions only. Thus, the contemporary needs for planning, delivery and monitoring of oral health care services at the population level are not fulfilled (13).

Studies that have evaluated the magnitude of 
the differences between ICDAS and DMFT/dmft at the population level are rare, and to our knowledge, these studies are focused only in children population (14). Although fewer in number compared to the child population, some researchers have accessed caries using ICDAS in clinical and epidemiological studies involving adults $(15,16)$. To our knowledge, no study has brought this aspect of comparison to epidemiological studies of the adult population, which should also have the diagnosis of caries and its treatment based on the philosophy of minimal intervention.

The aim of this study was to describe and compare findings regarding the prevalence and severity of dental caries when using the ICDAS and DMFT/dmft in an epidemiological study with children and their mothers.

\section{Material and Methods}

\section{Study Design and Sample Selection}

The survey was conducted in twelve primary care services (PCS) belonging to a hospital group in Porto Alegre, Rio Grande do Sul, Brazil. This study is part of a larger research on early childhood caries and the influence of social, psychological and behavioral variables, which was $\vec{s}$ approved by the Research Ethics Committee of Hospital Group Conceição (GHC), reference CEP-GHC/11-196.

All 674 children born in 2008 (3-4 years-old) and registered in one of the PCS were eligible, as were their mothers. The GHC is part of the Brazilian Ministry of Health, and provides access to care under Brazil's Public Health System. The GHC has an organized register of users which is considered a reference for Brazilian public health services.

A required sample size of 173 children was based on an estimated caries prevalence of $31 \%$ (using data from a neighboring city) (17), bidirectional alpha of 0.05 and beta of 0.10 . Assuming a $20 \%$ non-response rate, the sample size was set in 208 dyads of mother-child. The sample selection was randomly performed using a table with random numbers maintaining the proportion of children born in each PCS.

\section{Training and Calibration of Examiners}

Three examiners performed oral examinations using ICDAS criteria for caries detection. They were already familiar with ICDAS, and were trained previously using an E-learning Program (18). Calibration was performed at the Pediatric Dentistry Ambulatory of Federal University of Rio Grande do Sul. Ten children were examined and reexamined two weeks later. Tooth surface was considered as the unit analysis for Kappa calculation.

ICDAS consists of a two digits coding system, the first digit refers to the presence of sealants or any kind of restorations (codes range from $0-8$ ), and the second digit, to the various stages of carious lesion progression (codes range from 0-6). Four special codes can also be found (96 - tooth surface cannot be examined; 97 - tooth missing because of caries; 98 - tooth missing for other reasons; 99 - unerupted) (7).

\section{Epidemiological Survey and Data Collection}

Examinations were conducted within a 12-month period and each children's mother signed an informed consent. All data collection was performed at the participant's house. A phone call previously set the appointment. Families that phone numbers did not match were directly visited. This procedure was repeated at least 3 times before family was considered a non-response.

According to ICDAS protocol, all examinations in children and adults were performed with the dental surface clean and dry (19). After that, dental examination was conducted using house facilities and portable resources: air compressor (Nevoni, São Caetano), suction device (Ssplus, São Paulo), head light, WHO probe (Fava, São Paulo), tweezers (Fava, São Paulo), dental mirror (Sylkap, Curitiba) and cotton rolls. All personal protective equipment was used. Examination was performed in children and their mothers. For each dental surface, a code for dental condition and a code for caries status were recorded; afterwards, the caries conditions of the teeth were categorized according to the worse surface code. The authors did not assess the activity of the lesions.

In addition, mothers were interviewed and the following information was collected: age (in years), education of mothers (years of study), marital status, family monthly income (in Reais), child gender, number of sons and number of people living in the house.

\section{Statistical Analyses}

All collected data were inserted into a data entry programme specially designed for the epidemiological survey. The two-digits codes from ICDAS were collected and recorded by surfaces, and after, the codes were converted into the components of dmf-t/DMF-T index, in order to calculate caries experience in the following ways in both adults and children.

When the surface condition had code 3 or higher from ICDAS digit I, it was considered that the tooth was restored (the $\mathrm{f} / \mathrm{F}$ component from $\mathrm{dmf} / \mathrm{DMF}$ ). In relation to dental caries, after evaluation by surface, each tooth received the worst ICDAS code for one of its five surfaces. Regarding the literature $(9,14,20)$, it was used codes 3-6 to transform ICDAS to dmf/DMF - d/D. Code 97 from ICDAS was computed like the $\mathrm{m} / \mathrm{M}$ component of $\mathrm{dmf} / \mathrm{DMF}$. dmf/ DMF-T was obtained by adding ICDAS codes transformed to $\mathrm{D}, \mathrm{M}$, and $\mathrm{F}$. All the analysis (both ICDAS and DMF-T) was done at the tooth level. 
A descriptive analysis was performed for the variable frequency of caries lesions in both groups (mothers and children) for cut-off points CP1, CP2 and CP3 from ICDAS. Scores of ICDAS related to caries were analyzed according to three different cut-off points: $\mathrm{CP} 1$ (code.0: healthy, code 1-6: caries), CP2 (code 0-1: healthy, code 2-6: caries) and CP3 (code 0-2: healthy, code 3-6: caries). The frequency of caries by DMFT, dmft and ICDAS, presented by mean, standard deviation, minimum and maximum values were presented. To compare the prevalence of dental caries in the group of children and mothers in cut-off points CP1 and CP3 of ICDAS, the Fisher's exact test was used. The tests were worked on a significance level of $5 \%$.

\section{Results}

The sample comprised 300 participants, 150 children and 150 mothers. The mean inter-examiner Kappa value was 0.67 (ranged from 0.64 to 0.73 ). Description of the sample and sociodemographic characteristics can be found in Table 1.

It was observed that no child presented teeth extracted due to caries; in those who had some type of restoration $(9 \%), 73 \%$ were in primary molars, especially in the lower one, and with tooth-colored restorations. Regarding the mothers, $86 \%$ had at least 1 type of restoration (39\%

Table 1. Description of the sample

\begin{tabular}{lc}
\hline Children $(\mathrm{n}=150)$ & Mean $( \pm \mathrm{SD})$ \\
\hline Age & $3.34( \pm 0.5)$ \\
Male $(\mathrm{n}=70 ; 46.66 \%)$ & - \\
Female $(\mathrm{n}=80 ; 53.33 \%)$ & - \\
Mothers $(\mathrm{n}=150)$ & $33.66( \pm 7.6)$ \\
Age & $5.32( \pm 2.07)$ \\
Years of study & $\mathrm{R} \$ 2,240.08( \pm \mathrm{R} \$ 1,980.83)$ \\
Family income & $4.68( \pm 4.50)$ \\
$\begin{array}{l}\text { Number of people } \\
\text { living in the house } \\
\text { Number of children } \\
\text { living in the house }\end{array}$ & $2.22( \pm 1.27)$ \\
\hline
\end{tabular}

amalgam, $11 \%$ composite resin and $25 \%$ temporary or faulty restorations). Concerning teeth extracted due to caries, $25.4 \%$ of the mothers had at least one tooth lost and molars were the most frequently extracted.

In children, using ICDAS code CP1 as the cut-off point ( $\geq 1$ : presence of disease), $92 \%$ presented some clinical sign of disease. Using code CP2 as the cut-off point $(\geq 2$ : presence of disease), $84 \%$ presented carious lesions. When using score 3 as the cut-off point (code CP3), this number reduces to $31 \%$, showing that most of the children had only non-cavitated lesions (61\%). Regarding the mothers, there is no difference between the cut-off points $\mathrm{CP} 1$ and CP2 (97.3\% e $96.6 \%$, respectively). At the cut-off point CP3, the prevalence reduces $17.3 \%$, indicating that $80 \%$ of mothers had at least one cavitated lesion in the mouth. In relation to restorations, $9 \%$ of children had some sort of restoration (code 3 or $>$ ); that number increased considerably when mothers were examined (86\%). Regarding teeth extracted due to caries, $25.4 \%$ of adults had at least one tooth missing due to caries, while no child had lost any teeth because of it. When transforming these data to the DMFT index (using a cut-off 3-ICDAS), 34\% of children would present $\mathrm{dmft}$ $\geq 1(p<0.001)$, as well as $98 \%$ of adults $(p=1.000)$ (Table 2 and 3). Differences between different ICDAS cut-points and DMF-T are presented in Tables 2 and 3.

\section{Discussion}

The traditional DMFT index (10) bases the detection of caries at the cavitated level only and considers that its treatment should be based on fillings and extractions. The main and original finding of our study was that, in adult populations, the use of ICDAS added new information about non-cavitated lesions, but showed no statistically significant difference when compared with the DMFT index, since most mothers already had teeth with cavitated lesions, that had been restored or extracted due to caries. Also, the detection of non-cavitated lesions significantly influenced the findings in relation to caries when compared with the $\mathrm{dmf} / \mathrm{DMF}$ findings in preschool children. In this context, one should evaluate the purpose of the study in the adult population and the cost-effectiveness of using a more time-consuming method like the ICDAS. Moreover, the

Table 2. Prevalence of dental caries in children and mothers, according to ICDAS and DMFT index

\begin{tabular}{|c|c|c|c|c|c|c|c|}
\hline & $\begin{array}{c}\text { CP1 - ICDAS-1 } \\
\text { or }>1 \\
\mathrm{~N}(\%)\end{array}$ & $\begin{array}{c}\mathrm{CP} 2 \text { - ICDAS-2 } \\
\text { or }>2 \\
\mathrm{~N}(\%)\end{array}$ & $\begin{array}{c}\text { CP3 - ICDAS-3 } \\
\text { or }>3 \\
\mathrm{~N}(\%)\end{array}$ & $\begin{array}{l}\text { Restoration } \\
\text { presence } \\
\mathrm{N}(\%)\end{array}$ & $\begin{array}{c}\text { Extraction } \\
\text { duo to caries } \\
\mathrm{N}(\%)\end{array}$ & $\begin{array}{l}\text { DMF-T } / \mathrm{dmf}-\mathrm{t} \\
\quad>\text { or }=1\end{array}$ & $\mathrm{p}$ value \\
\hline Children $(n=150)$ & $138(92 \%)$ & $126(84 \%)$ & 47 (31.3\%) & $14(9.3 \%)$ & $0(0 \%)$ & $51(34 \%)$ & $\mathrm{P}<0.001 \mathrm{a}$ \\
\hline Mothers $(n=150)$ & $146(97.3 \%)$ & $145(96.6 \%)$ & $120(80 \%)$ & $129(86 \%)$ & 38 (25.4\%) & 147 (98\%) & $\mathrm{P}=1.000$ \\
\hline
\end{tabular}

aFisher's exact test (between $\mathrm{CP} 1$ and $\mathrm{CP} 3$ ). 
DMF-T index underestimates the presence of the disease in children evaluated, as it ignored the most prevalent clinical presentation of caries found in the studied sample, non-cavitated lesions.

This study shows that the criteria recommended by WHO can be used for adults without losing much information. However, in children, a relevant amount of information in estimating disease burden is lost, and for those who make decisions on health it is essential. This may lead to an underestimation of caries in populations, primarily children, and result in changes in the implementation of caries prevention actions by stakeholders. It can be considered that the non-cavitated lesions are very common but they have a low rate of progression (21), without ignoring the differential impact of "untreated" initial caries and "actual burden of caries - cavities", especially when considering the implementation of politic measures to control the disease.

Research in epidemiology has an objective of making a population diagnosis, which is important for decision making in health and should therefore be able to generate accurate estimates of disease burden. These accurate estimates are also important because, in order to develop and plan effective health actions, one cannot work with diagnostic criteria that only account for the disease at a cavitation level, looking for all of the knowledge that has been accumulated regarding caries disease to date.

We must, therefore, consider the meaning of epidemiological investigation. If it is of interest that the oral health care planners to estimate dental caries figures for the purpose of determining clinical care and treatment needs, the DMF-T index may be sufficient. On the other hand, if the action also has the objective of stalling and reversing the carious process through population-based, prevention oriented actions, one has to consider whether it is important to estimate the lesions at an earlier stage. As some studies raise difficulties regarding the use of ICDAS because it is time-consuming, adding relevant costs to survey implementation, this should be prioritized in epidemiological surveys focused on the pediatric population.
Other finding of the present paper was that the detection of non-cavitated lesions was suitable and reliable when performed under field conditions. Some studies $(22,23)$ support the use of a modification of WHO index allowing the detection of non-cavitated lesions; however, the most current version of the WHO manual gives no information or reference about these changes (10). Knowing that obtaining good conditions for conducting a detailed clinical examination in the context of an epidemiological study is a challenge, this study described a methodology to collect data with sufficient flexibility to be used in a variety of settings and situations in the field. Concerning the reliability of the diagnosis of non-cavitated lesions in epidemiology studies, the values obtained were compatible with substantial agreement.

Any method that aims to register non-cavitated lesions requires more time for the clinical examination to be performed when compared to the traditional system recommended by the WHO. This statement is in accordance with the literature, which showed that the choice of a method to detect non-cavitated lesions may take twice as long $(9,24)$. It is important to take into account the experience of examiners, since the knowledge and previous training positively influences the time of data collection (18). The ICDAS website provides an e-learning Program for prior training (www.icdas.org). The information obtained through the detection of non-cavitated lesions should, in one way or another, compensate the extra time during the fieldwork if this information was essential to meet the objective of the research.

To control biases in the study, three experienced, trained and calibrated examiners performed the data collection; when $50 \%$ of the sample was reached, a new calibration was performed by reviewing $10 \%$ of the sample. All collected data were recorded by an undergraduate student who was unaware of the value of each code. This random sample is representative of Northern District of the City of Porto Alegre/Brazil. Additional studies are needed to extrapolate these findings. A limitation of the study is that the examination was not carried using the traditional index

Table 3. Severity distribution of caries (ICDAS digit I) in children and mothers, according to ICDAS and DMFT index

\begin{tabular}{|c|c|c|c|c|}
\hline & $\begin{array}{l}\text { Non-cavitated lesions } \\
\text { (ICDAS 1-2) }\end{array}$ & $\begin{array}{l}\text { Cavitated lesions } \\
\text { (ICDAS 3-4-5-6) }\end{array}$ & Mean ICDAS $( \pm$ SD) & Mean DMF-T /dmf-t $( \pm$ SD) \\
\hline Female children & $49(32 \%)$ & $25(16.6 \%)$ & - & - \\
\hline Male children & $42(28 \%)$ & $22(14.6 \%)$ & - & - \\
\hline Total of children & $91(60 \%)$ & 47 (31.3\%) & $2.52( \pm 1.53)$ & $1.39( \pm 2.73)$ \\
\hline Mothers & 25 (16.6\%) & $121(80.6 \%)$ & $4.04( \pm 1.60)$ & $9.03( \pm 4.90)$ \\
\hline
\end{tabular}


recommended by $\mathrm{WHO}$ with the objective of comparing the accuracy of the methods discussed. However, the literature brings findings in this direction and guides the best cut-off point to be made to transforming the data collected with the ICDAS in DMFT/dmft. When we started planning the survey, ICDAS did not advocate activity assessment of the disease, the reason we did not asses it.

Each epidemiological index has particular characteristics that also influence the choice of which index to use. The ICDAS, based on best available evidence for detecting early and later stage caries severity, have different scores for surface and caries evaluation and should lead to the acquisition of better quality information which could then be used to inform decisions about appropriate diagnosis, prognosis, and clinical management of dental caries at both the individual and public health levels. The WHO recommended index, DMFT/dmft, is used worldwide to measure the prevalence of dental caries based on decayed, missing and filled teeth due to caries. It has the advantage of not requiring prior prophylaxis, lighting and drying of the dental element. However, it only recognizes one condition by surface reducing the sensitivity of the method and therefore its application in planning and health promotion.

As well as ICDAS being a coding classification there are simple, standard examination processes employed as part of the system. An important element of the examination is the cleaning of teeth to aid detection since caries forms where there has been plaque stagnation. In addition, the use of compressed air is necessary to reveal the earliest visual signs of caries.

In conclusion, the choice of which is the best index for epidemiological surveys will depend on the purpose of the research and the target population: if it is to estimate the needs of the population to determine clinical care in children and adults, the DMFT/dmft may be sufficient. However, if the objective is to have a more comprehensive diagnosis of dental caries at the population level in order to develop preventive strategies, to halt and reverse the disease, the detection of non-cavitated lesions becomes important, mainly in young children.

\section{Acknowledgements}

This work is linked to an integrated research project entitled "Evaluation of the association between parental bonding representation, depression and maternal anxiety and early childhood caries". It was approved by the Ethics Committee on Research Hospital Group Conceição (GHC-CEP) on 09/11/2011, with the number of 11-196 process, and financed with funds granted by the Universal Notice "National Counsel of Technological and Scientific Development" 479894 / 2010-8 and Notice Researcher Gaucho Support of the State of Rio Grande do Sul Research Foundation 11 / 1368-4.

\section{Resumo}

0 objetivo deste estudo foi descrever e comparar os achados sobre a prevalência e severidade da cárie dentária ao utilizar ICDAS e CPOD/ ceod em um estudo epidemiológico com crianças e suas mães. Este estudo transversal avaliou 150 pré-escolares e suas mães. Os dados foram coletados utilizando-se o ICDAS e depois transformados em CPOD/ceod. Os códigos do ICDAS relacionados à cárie foram analisados de acordo com três diferentes pontos de corte: $\mathrm{CP} 1$ (0-hígido/1-6-cárie), CP2 (0-1 hígido/2-6-cárie) e CP3 (0-2 hígido/3-6-cárie), representando o D/d do indice $\mathrm{CPOD} /$ ceod. Os códigos do ICDAS referentes às restaurações, exceto selantes, foram considerados o 0/o e o código 97 do ICDAS como o P/e do indice $\mathrm{CPOD} / \mathrm{ceod}$. A prevalência de cárie e sua severidade com o ICDAS foram de $92 \%$, $84 \%$ e $31,3 \%$ em crianças e $97,3 \%, 96,6 \%$ e $80 \%$ em adultos de acordo com o CP1 / CP2 / CP3, respectivamente. Admitindo o ponto de corte $\mathrm{CP} 3$ como o padrão para a transformação de achados do ICDAS em CPOD/ceod, foi observado que o indice CPOD/ceod subestimaria $60 \%$ das lesões não cavitadas em crianças e $16,6 \%$ em adultos. 0 CPOD/ ceod subestima a presença da doença ao desconsiderar as lesões não cavitadas na população pediátrica avaliada. A escolha de qual é o melhor indice para levantamentos epidemiológicos vai depender do propósito da pesquisa e da população-alvo: se o objetivo for estimar as necessidades da população para determinar cuidados clínicos em crianças e adultos, o CPOD/ceod pode ser suficiente. No entanto, se o objetivo for ter um diagnóstico mais abrangente da doença ao nivel da população, a fim de desenvolver estratégias preventivas, para paralisar e reverter a doença, a detecção de lesões não cavitadas torna-se importante, principalmente em crianças pequenas.

\section{References}

1. Constante $H M$, Souza ML, Bastos JL, Peres MA. Trends in dental caries among Brazilian schoolchildren: 40 years of monitoring (1971-2011). Int Dent J 2014;64:181-186.

2. Misra S, Tahmassebi JF, Brosnan M. Early childhood caries - a review. Dent Update 2007;34:556-558,61-62,64.

3. Tinanoff $N$, Reisine $\mathrm{S}$. Update on early childhood caries since the Surgeon General's Report. Acad Pediatr 2009;9:396-403.

4. Amorim RG, Figueiredo MJ, Leal SC, Mulder J, Frencken JE. Caries experience in a child population in a deprived area of Brazil, using ICDAS II. Clin Oral Investig 2012;16:513-520.

5. Ericson D. The concept of minimally invasive dentistry. Dent Update 2007;34:9-10,2-4,7-8.

6. Assaf AV, de Castro Meneghim M, Zanin L, Tengan C, Pereira AC. Effect of different diagnostic thresholds on dental caries calibration - a 12 month evaluation. Community Dent Oral Epidemiol 2006;34:213-219.

7. Pitts N. "ICDAS" - an international system for caries detection and assessment being developed to facilitate caries epidemiology, research and appropriate clinical management. Community Dent Health 2004;21:193-198.

8. Ismail Al, Sohn W, Tellez M, Amaya A, Sen A, Hasson H, et al.. The International Caries Detection and Assessment System (ICDAS): an integrated system for measuring dental caries. Community Dent Oral Epidemiol 2007;35:170-178.

9. Braga MM, Oliveira LB, Bonini GA, Bonecker M, Mendes FM. Feasibility of the International Caries Detection and Assessment System (ICDASII) in epidemiological surveys and comparability with standard World Health Organization criteria. Caries Res 2009;43:245-249.

10. WHO. Oral Health Surveys: Basic Methods. 2013; 5th ed.

11. Carvalho JC, Van Nieuwenhuysen JP, D'Hoore W. The decline in dental caries among Belgian children between 1983 and 1998. Community Dent Oral Epidemiol 2001;29:55-61.

12. Carvalho JC, D'Hoore W, Van Nieuwenhuysen JP. Caries decline in the primary dentition of Belgian children over 15 years. Community Dent Oral Epidemiol 2004 Aug;32:277-282.

13. Pitts NB. Modern concepts of caries measurement. J Dent Res 2004;83 Spec No C:C43-C47.

14. Clara J, Bourgeois D, Muller-Bolla M. DMF from WHO basic methods to ICDAS II advanced methods: a systematic review of literature. Odontostomatol Trop 2012;35:5-11.

15. Carta G, Cagetti MG, Cocco F, Sale S, Lingström P, Campus G. Caries-risk profiles in Italian adults using computer caries assessment system and 
ICDAS. Braz Oral Res 2015;29:1-8.

16. Brown JP, Amaechi BT, Bader JD, Shugars D, Vollmer WM, Chen C et al. Community Dentistry and Oral Epidemiology 2015;43:208-216.

17. Ferreira SH, Beria JU, Kramer PF, Feldens EG, Feldens CA. Dental caries in 0 - to 5-year-old Brazilian children: prevalence, severity, and associated factors. Int J Paediatr Dent 2007;17:289-296.

18. Rodrigues JA, de Oliveira RS, Hug I, Neuhaus K, Lussi A. Performance of experienced dentists in Switzerland after an e-learning program on ICDAS occlusal caries detection. J Dent Educ 2013;77:1086-1091.

19. Ekstrand KR, Martignon S, Ricketts DJ, Qvist V. Detection and activity assessment of primary coronal caries lesions: a methodologic study. Oper Dent 2007;32:225-235.

20. Iranzo-Cortes JE, Montiel-Company JM, Almerich-Silla JM. Caries diagnosis: agreement between WHO and ICDAS II criteria in epidemiological surveys. Community Dent Health 2013;30:108-111.

21. Guedes RS, Piovesan C, Floriano I, Emmanuelli B, Braga MM, Ekstrand $\mathrm{KR}$, et al. Risk of initial and moderate caries lesions in primary teeth to progress to dentine cavitation: a 2-year cohort study. Int J Paediatr Dent 2016;26:116-124.
22. Jain SK, Pushpanjali K, Reddy SK, Gaikwad R, Deolia S. Comparison of different caries diagnostic thresholds under epidemiological and clinical settings among 7-15 year old school children from Bangalore city. J Int Soc Prev Community Dent 2013;3:85-91.

23. Machale PS, Hegde-Shetiya $S$, Shirahatti R, Agarwal D. Assessment of non-cavitated and cavitated carious lesions among 12- to 15-year-old government and private school children in Pune, Maharashtra, India. Oral Health Prev Dent 2014;12:117-124.

24. Mendes FM, Braga MM, Oliveira LB, Antunes JL, Ardenghi TM, Bonecker M. Discriminant validity of the International Caries Detection and Assessment System (ICDAS) and comparability with World Health Organization criteria in a cross-sectional study. Community Dent Oral Epidemiol 2010;38:398-407.

Received April 25, 2016 Accepted August 1, 2016 